\title{
Taxonomic re-assessment and phylogenetic relationships of Miocene homonymously spiral-horned antelopes
}

\author{
Dimitris S. Kostopoulos \\ Acta Palaeontologica Polonica 59 (1), 2014: 9-29 doi: http://dx.doi.org/10.4202/app.2011.0013
}

A morphological reappraisal of Middle Miocene and Early Pliocene antelopes with homonymously twisted horncores (i.e., with the left horncore twisted clockwise from the base up) and an additional re-description of some critical Greek specimens allows a revision of the current taxonomy at the species and genus level. A parsimony analysis recognizes Hispanodorcas, Oioceros, Samodorcas, Samotragus, Paraoioceros, and Urmiatherium as distinct lineages of the subtribe Oiocerina. The latter emerged during the Astaracian (ca. 14-11.5 Ma), and radiated in Eurasia during the mid-late Vallesian (ca. 10-9 Ma), resulting in a great variety of genera with unique combinations of morpho-ecological adaptations. The suprageneric relationships of Oiocerina are poorly understood, but their closest ancestors possibly lie within or close to the Middle Miocene "hypsodontines", and inside Antilopinae.

Key words: Mammalia, Bovidae, Oiocerina, systematics, phylogeny, zoogeography, ecology, Miocene, Greece.

Dimitris S. Kostopoulos [kㅏostop@geo.auth.gr], University of Thessaloniki, Department of Geology, Laboratory of Paleontology, 54124 Thessaloniki, Greece.

This is an open-access article distributed under the terms of the Creative Commons Attribution License (for details please see creativecommons.org), which permits unrestricted use, distribution, and reproduction in any medium, provided the original author and source are credited. 
